\title{
Combustion Characteristics of Several Flammable Gases with Chlorine Trifluoride
}

\author{
HIDEO OHTANI, LEE SAN GON and YOICHI UEHARA \\ Department of Safety Engineering, Faculty of Engineering \\ Yokohama National University \\ 156 Tokiwadai, Hodogaya-Ku, Yokohama 240, Japan
}

\begin{abstract}
There are several flammable gases used in semiconductor industries, and some oxidizing gas such as chlorine trifluoride $\left(\mathrm{ClF}_{3}\right)$ is also used in the same production apparatus. As knowledge of the combustion characteristics of flammable gases with oxidizing gases other than oxygen are lacking, an experimental study to evaluate combustion characteristics was performed. Chlorine trifluoride, the oxidizing gas used in this study was commercialized recently for etching and cleaning purposes because of its powerful oxidizing ability. As flammable gases, tetraethyl orthosilicate(TEOS: $\left.\mathrm{Si}\left(\mathrm{OC}_{2} \mathrm{H}_{5}\right)_{4}\right)$, hydrogen $\left(\mathrm{H}_{2}\right)$ and ammonia $\left(\mathrm{NH}_{3}\right)$ were investigated.
\end{abstract}

These gases are toxic, except for hydrogen, and have high reactivity, so these gases were first diluted with nitrogen separately. The diluted TEOS and ammonia gases were found to ignite spontaneously while being mixed with the diluted $\mathrm{CIF}_{3}$ gas. On the other hand, the diluted hydrogen gas could be mixed with the diluted $\mathrm{ClF}_{3}$ gas without spontaneous ignition. And a $\mathrm{H}_{2} / \mathrm{ClF}_{3} / \mathrm{N}_{2}$ mixture could be ignited by an electric spark. Therefore, for TEOS and ammonia, "flammable limit" means the limit of spontaneous combustion, and for hydrogen the flammable limit means the usual limit of ignitability by an external ignition source.

The flammability diagrams of TEOS/ClF $3 / \mathrm{N}_{2}, \mathrm{NH}_{3} / \mathrm{ClF}_{3} / \mathrm{N}_{2}$ and $\mathrm{H}_{2} / \mathrm{ClF}_{3} / \mathrm{N}_{2}$ mixtures were determined. And reaction kinetics between them were discussed from observed combustion characteristics.

KEYWORDS:Chlorine trifluoride, TEOS, hydrogen, ammonia, flammability diagram, spontaneous ignition.

\section{INTRODUCTION}


In semiconductor industries, many flammable gases 1 ),2) are used for doping and so on, and several oxidizing gases are used for etching and cleaning. Explosion accidents have happened concerning silane $\left(\mathrm{SiH}_{4}\right)$ such as one at Berkeley Heights, NJ. on March 17 , 1988, at Kodaira, a suburban Tokyo metropolis, on December 13,1989, and one at Osaka University on October 2, 1991. At least, the first and the third accidents suggest the possibility of accidental mixing of a flammable gas with an oxidizing gas because they are both supplied to the same gas line in the present production system of semiconductors. However, the explosive hazard of a flammable gas usually has been assessed against air or oxygen. Evaluation of combustion characteristics in other oxidizing gases is indispensable for preventing explosive accidents of semiconductor gases.

Chlorine trifluoride $\left(\mathrm{ClF}_{3}\right)$ was commercialized recently to utilize its high reactivity in an oxidizing reaction. Combustion characteristics of flammable gases with $\mathrm{ClF}_{3}$ are not known well. The evaluation of explosion hazard of $\mathrm{ClF}_{3}$ has just been started 3 ), 4). Previous studies of the combustion characteristics of $\mathrm{SiH}_{4}$ and $\mathrm{SiH}_{2} \mathrm{Cl}_{2}$ with $\mathrm{ClF}_{3}$ revealed the powerful oxidizing ability of $\mathrm{ClF}_{3} . \quad \mathrm{ClF}_{3}$ was powerful enough to cause spontaneous ignition of the gases. In this study, combustion characteristics of tetraethyl orthosilicate(TEOS: $\left.\mathrm{Si}\left(\mathrm{OC}_{2} \mathrm{H}_{5}\right)_{4}\right)$, ammonia $\left(\mathrm{NH}_{3}\right)$ and hydrogen $\left(\mathrm{H}_{2}\right)$ with $\mathrm{ClF}_{3}$ were investigated experimentally. These gases are also frequently used in semiconductor industries.

\section{EXPERIMENTAL PROCEDURE}

Experimental apparatus consisted mainly of two dilution vessels and an explosion vessel all made of stainless steel(Fig. 1), of the inner space of the explosion vessel was $10 \mathrm{~cm}$ in diameter and $12 \mathrm{~cm}$ high. First the whole experimental apparatus was evacuated. Then, both $\mathrm{ClF}_{3}$ and one of flammable gases were diluted with nitrogen in the dilution vessels,

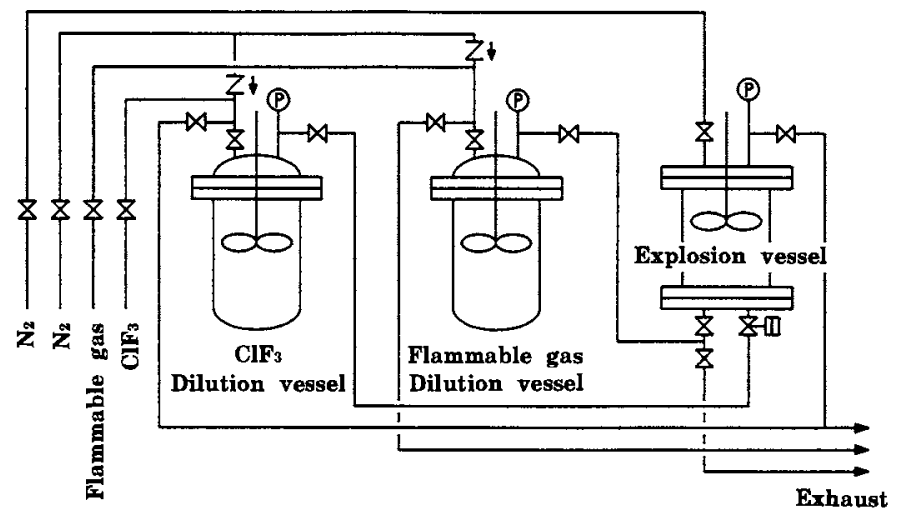

FIGURE 1. Schematic diagram of the experimental apparatus. 
respectively. Concentrations of the diluted flammable gas and the diluted $\mathrm{ClF}_{3}$ gas were determined from partial pressures in the dilution vessels. The diluted flammable gas was introduced first into the explosion vessel, at pressure up to $50 \mathrm{kPa}$. The diluted $\mathrm{ClF}_{3}$ gas was injected into the explosion vessel containing the diluted flammable gas by pressure difference between the dilution and the explosion vessels up to $100 \mathrm{kPa}$. In a case of TEOS or ammonia as flammable gas ignition occurred spontaneously by the injection of the diluted $\mathrm{ClF}_{3}$ gas when compositions of the diluted gases were in flammable range. In a case of hydrogen as a flammable gas spontaneous ignition did not occur, so an electric spark was applied after the diluted $\mathrm{ClF}_{3}$ gas was well mixed in the explosion vessel. The pressure and temperature histories during the injection of the diluted $\mathrm{CIF}_{3}$ gas into the explosion vessel or after an electric spark was applied were measured by using a pressure transducer and a sheathed CA-thermocouple having $0.5 \mathrm{~mm}$ sheath diameter. Their outputs were recorded by a storage oscilloscope(HITACHI VC-6045). No appreciable temperature variation was observed near the flammable limit in a case of the spontaneous ignition. Therefore, discussion in the following section will be focused on the pressure history.

The tested gases were supplied as follows. $\mathrm{ClF}_{3}$ was supplied as a liquefied gas in a 1 litre cylinder. TEOS is liquid at the room temperature, so its vapor was drawn from a flask containing liquid TEOS. Ammonia and hydrogen were supplied in 10 litre cylinders

\section{EXPERIMENTAL RESULTS AND DISCUSSION}

\section{Pressure History}

Figure 2 shows an example of the pressure history after the initiation of the diluted $\mathrm{ClF}_{3}$ gas injection into the explosion vessel. A pressure history labeled as blank in the figure shows the history for the blank test in which pure $\mathrm{N}_{2}$ was injected into the explosion vessel The pressure histories for the diluted $\mathrm{ClF}_{3}$ gas differ obviously from the blank curve. As mentioned before spontaneous ignition occurred when the diluted TEOS or ammonia gas was in the explosion vessel and pressure histories for them show larger values than the blank curve. The difference between these curves was considered to be caused by heat release of the oxidation reaction meaning that the tested composition is in the flammable range. As the actual composition at a point where the reaction started was unknown because ignition occurred during injection, concentration of $\mathrm{ClF}_{3}$ and TEOS or ammonia will be represented by the values in the dilution vessels.

It should be noted that in case of TEOS the pressure increment appeared after the diluted $\mathrm{ClF}_{3}$ gas had been injected completely into the explosion vessel. But the pressure increment was relatively small when the concentration of TEOS was low(TEOS 1). A distinct pressure peak appeared when concentration of TEOS was relatively high(TEOS 2). Although spontaneous ignition occurred similarly in case of the diluted ammonia gas, the pressure increment appeared just after the initiation of the diluted $\mathrm{CIF}_{3}$ gas injection. On the other hand, no spontaneous ignition occurred with hydrogen as a flammable gas. Therefore the pressure history for hydrogen was identical with the blank curve until the 


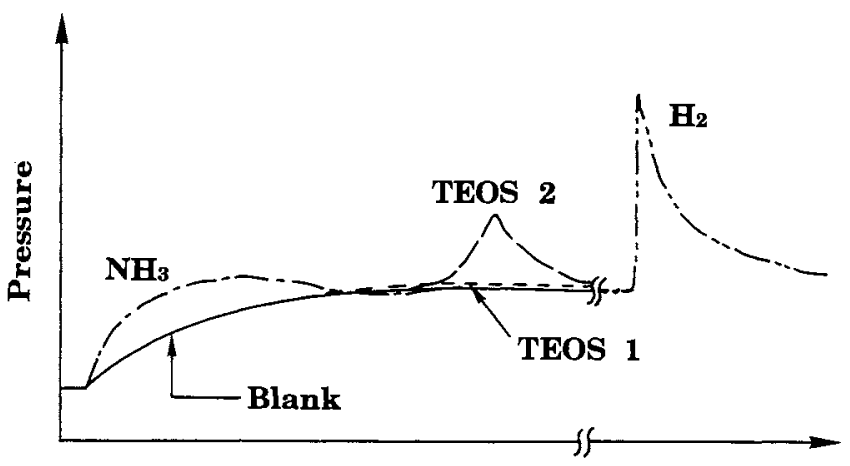

Time

FIGURE 2. Typical pressure histories for TEOS, ammonia, and hydrogen.

well mixed hydrogen/ $\mathrm{ClF}_{3} / \mathrm{N}_{2}$ mixture was ignited electrically. Accordingly, the flammable composition for the mixture in the explosion vessel was determined clearly in a case of hydrogen.

\section{Tetraethyl Orthosilicate(TEOS)}

Figure 3 shows relation between pressure increment and concentration of the diluted $\mathrm{ClF}_{3}$ gas which was injected into the explosion vessel. In this figure the pressure increment means the maximum difference between pressure histories for the actual and the blank tests. Concentration of the diluted TEOS gas which was introduced into the explosion vessel before the injection of the diluted $\mathrm{ClF}_{3}$ gas was set to $0.5 \mathrm{vol} \%$ and $0.25 \mathrm{vol} \%$. This figure shows there are apparently three regimes. No pressure increment appears in the first regime under $0.9 \mathrm{vol} \%$ of $\mathrm{ClF}_{3}$, i.e. the first regime is out of the flammable range. In the second regime between 0.9 vol\% and $2.5 \mathrm{vol} \%$ of $\mathrm{ClF}_{3}$, a little pressure increment was observed. The pressure increment was constant independently of the concentration of $\mathrm{ClF}_{3}$. In the third regime over 2.5 vol\% of $\mathrm{ClF}_{3}$, the pressure increment increased linearly with the increase of $\mathrm{ClF}_{3}$ concentration. Some chemical reaction occurred in the second and the third regimes, but the reaction was limited to some extent in the second regime, and more complete reaction occurred in the third regime

Figure 4 shows variation of the elapsed time to reach the maximum pressure increment shown in Fig. 3. This figure shows the same three regions as Fig. 3. The maximum pressure increment appeared about 5 seconds after the initiation of the injection in the second region. At the boundary between the second and the third regions, the elapsed time was delayed slightly. Then the elapsed time decreased as the $\mathrm{ClF}_{3}$ concentration increased in the third region. It took about one second to inject the prescribed amount of the diluted $\mathrm{ClF}_{3}$ gas into the explosion vessel. Therefore, the main part of the reaction between $\mathrm{ClF}_{3}$ and TEOS occurred after the injection terminated. 


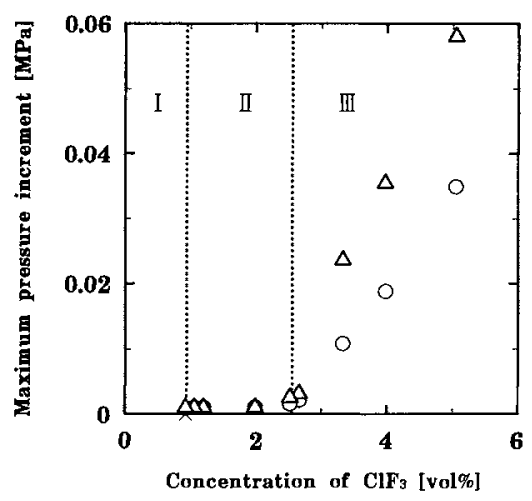

FIGURE 3. Relation between the pressure increment and the $\mathrm{ClF}_{3}$ concentration for TEOS. Concentration of the diluted TEOS gas was $0.5 \mathrm{vol} \%(\triangle)$ or $0.25 \mathrm{vol} \%(O)$.

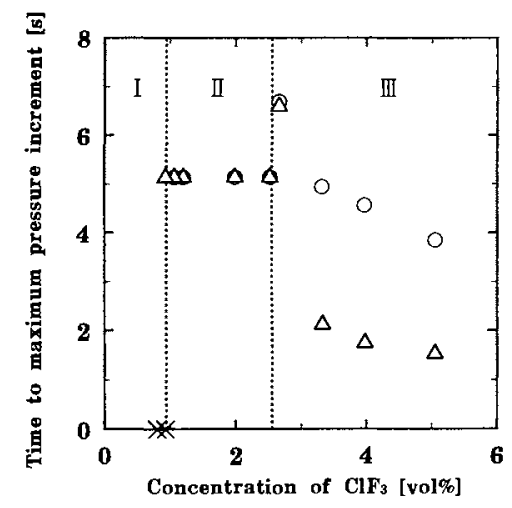

FIGURE 4. Relation between the elapsed time to reach the maximum pressure increment and the $\mathrm{ClF}_{3}$ concentration for TEOS. Concentration of the diluted TEOS gas was 0.5 vol $\%(\triangle)$ or 0.25 vol $\%(O)$.

From the result shown in Figs. 3 and 4, several reaction mechanisms between $\mathrm{ClF}_{3}$ and TEOS were supposed and discussed. However, any clear image of the reaction mechanism could not be attained. The most important finding is that the reaction phenomena can be classified at the same concentration of $\mathrm{ClF}_{3}$ independently of the TEOS concentration. This is considered to mean that a decomposition reaction of $\mathrm{ClF}_{3}$ alone governs the whole reaction. But this supposition can not the explain presence of the second region. In the second region the $\mathrm{ClF}_{3}$ concentration did not affect the maximum pressure increment and the elapsed time. To confirm the reaction mechanism between $\mathrm{ClF}_{3}$ and TEOS, a more thorough investigation is indispensable. 
Besides, the complete combustion reaction between them is expressed as

$$
\mathrm{Si}\left(\mathrm{OC}_{2} \mathrm{H}_{5}\right)_{4}+12 \mathrm{C \ell F}_{3} \rightarrow \mathrm{SiF}_{4}+8 \mathrm{CF}_{4}+12 \mathrm{HC} \ell+4 \mathrm{H}_{2} \mathrm{O} . \quad \Delta \mathrm{H}=-6493.2 \mathrm{~kJ} / \mathrm{mol}
$$

But $\mathrm{Stein}^{5)}$ reported that $\mathrm{ClF}_{3}$ decomposed at $220^{\circ} \mathrm{C}$ like

$$
C \ell F_{3} \rightarrow F_{2}+C \ell F . \quad \Delta \mathrm{H}=108.7 \mathrm{~kJ} / \mathrm{mol}
$$

This decomposition reaction was considered to occur before the complete combustion reaction. Taking this decomposition reaction into account and assuming that relatively stable CIF did not react with TEOS, the complete combustion reaction was modified like

$$
\mathrm{Si}\left(\mathrm{OC}_{2} \mathrm{H}_{5}\right)_{4}+24 \mathrm{C \ell F} \mathrm{F}_{3} \rightarrow \mathrm{SiF}_{4}+8 \mathrm{CF}_{4}+12 \mathrm{HF}+4 \mathrm{H}_{2} \mathrm{O}+24 \mathrm{C \ell F} . \Delta \mathrm{H}=-7934.4 \mathrm{~kJ} / \mathrm{mol}
$$

According to this reaction, TEOS can react with twofold amount of $\mathrm{ClF}_{3}$ compared with the complete combustion reaction, and release larger heat than the complete combustion reaction.

Figure 5 shows the flammability diagram for the TEOS/ClF $3 / \mathrm{N}_{2}$ mixture. Strictly speaking, this flammable range is that where the spontaneous ignition occurred. It is different from the usual flammable range where a flammable mixture is ignitable externally. However, an electric spark could not ignite a mixture out of the flammable range in Fig. 5 , so the flammable range in Fig. 5 is believed to coincide with the usual flammable range. Open circles means the data belong to the second region(TEOS 1), and solid circles means those belong to the third region(TEOS 2). The lower limiting concentration for $\mathrm{ClF}_{3}$ and TEOS are ca. $0.6 \mathrm{vol} \%$ and ca. $0.2 \mathrm{vol} \%$, respectively.

\section{Ammonia}

Figure 6 shows variations of the pressure increment and the elapsed time to reach the maximum pressure increment vs. the concentration of $\mathrm{ClF}_{3}$. The concentration of the diluted $\mathrm{NH}_{3}$ gas was kept at $1.45 \mathrm{vol} \%$. The minimum concentration of $\mathrm{ClF}_{3}$ at which the

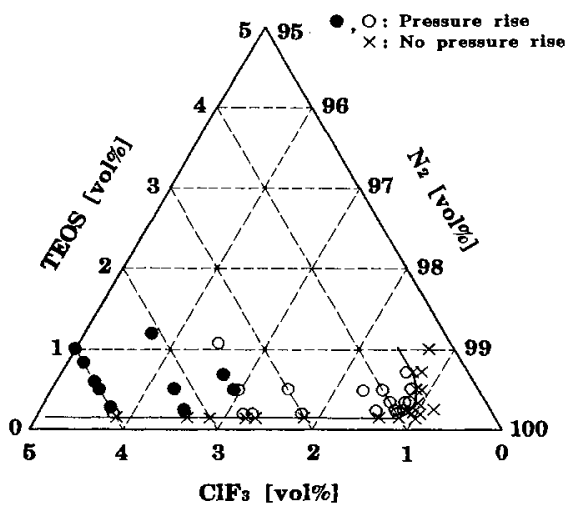

FIGURE 5. Flammability diagram of the TEOS/ $\mathrm{ClF}_{3} / \mathrm{N}_{2}$ mixture. 
pressure increment appeared was $0.28 \mathrm{vol} \%$. Above the limit concentration the pressure increment increased and the elapsed time decreased linearly as the $\mathrm{ClF}_{3}$ concentration increased.

Figure 7 shows the flammability diagram of the $\mathrm{NH}_{3} / \mathrm{ClF}_{3} / \mathrm{N}_{2}$ mixture. From this diagram the lower limiting concentration for $\mathrm{NH}_{3}$ is $0.07 \mathrm{vol} \%$ and that for $\mathrm{ClF}_{3}$ is $0.14 \mathrm{vol} \%$. On the other hand, the complete combustion reaction between $\mathrm{ClF}_{3}$ and $\mathrm{NH}_{3}$ is expressed as

$$
\mathrm{NH}_{3}+\frac{3}{4} \mathrm{C \ell F}_{3} \rightarrow 2 \frac{1}{4} \mathrm{HF}+\frac{3}{4} \mathrm{HC} \ell+\frac{1}{2} \mathrm{~N}_{2} . \quad \Delta \mathrm{H}=-516.1 \mathrm{~kJ} / \mathrm{mol}
$$

Previously mentioned ratio for the limiting concentrations of $\mathrm{NH}_{3}$ and $\mathrm{ClF}_{3}$ is $1: 2$. The ratio is much smaller than that of the complete combustion reaction, i.e. $4: 3$.

With the assumption that $\mathrm{ClF}_{3}$ decomposed before the combustion reaction as mentioned above, the former complete combustion reaction was modified as

$$
\mathrm{NH}_{3}+\frac{3}{2}{\mathrm{C} \ell F_{3}} \rightarrow 3 \mathrm{HF}+\frac{3}{2} \mathrm{C} \ell F+\frac{1}{2} \mathrm{~N}_{2} . \quad \Delta \mathrm{H}=-604.1 \mathrm{~kJ} / \mathrm{mol}
$$

This reaction has larger heat of reaction than the complete combustion reaction, and a ratio of concentrations for $\mathrm{NH}_{3}$ and $\mathrm{ClF}_{3}$ has closer value with the experimental one than the complete combustion reaction.

\section{Hydrogen}

Figure 8 shows variations of the maximum pressure and the elapsed time to reach the maximum pressure vs. the concentration of $\mathrm{ClF}_{3}$. In the case of hydrogen no spontaneous

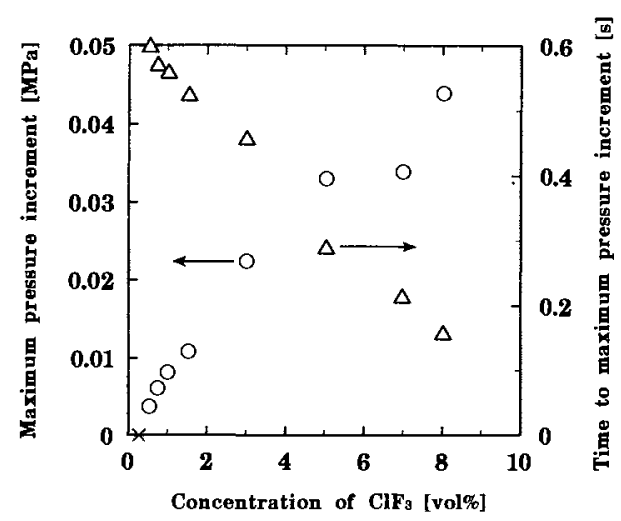

FIGURE 6. Variation of the pressure increment and the elapsed time to the maximum pressure increment with the $\mathrm{ClF}_{3}$ concentration for ammonia. Concentration of ammonia was $1.45 \mathrm{vol} \%$. 


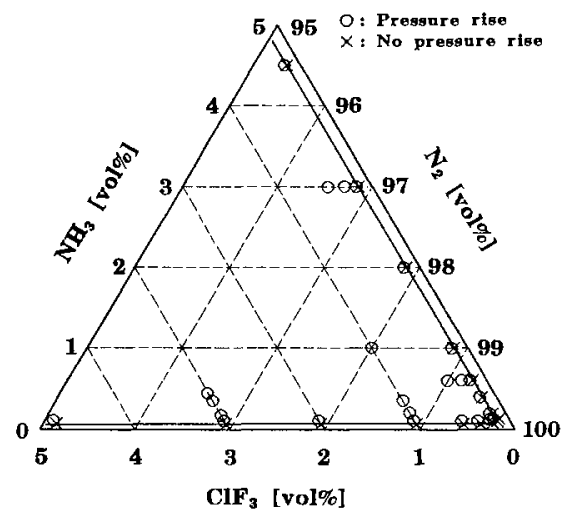

FIGURE 7. Flammability diagram of the $\mathrm{NH}_{3} / \mathrm{ClF}_{3} / \mathrm{N}_{2}$ mixture

ignition occurred, so the maximum pressure was attained after an electric spark was applied to the $\mathrm{H}_{2} / \mathrm{ClF}_{3} / \mathrm{N}_{2}$ mixture stirred well in the explosion vessel. In this case, the concentration for each composition is that for the mixture in the explosion vessel, not in the dilution vessel. The concentration of $\mathrm{H}_{2}$ was kept at $3.0 \mathrm{vol} \%$ and the initial pressure in the explosion vessel was $0.05 \mathrm{MPa}$. In this figure the maximum pressure means the difference between the absolute maximum pressure and the initial pressure. The minimum concentration of $\mathrm{ClF}_{3}$ at which an explosion occurred was $1.7 \mathrm{vol} \%$. Beyond the limit concentration the pressure increment increased and the elapsed time decreased linearly as the $\mathrm{ClF}_{3}$ concentration increased up to 3.0 vol\% $\mathrm{ClF}_{3}$. Higher concentrations of $\mathrm{ClF}_{3}$ caused little effect on the maximum pressure and the elapsed time. This means that $\mathrm{ClF}_{3}$

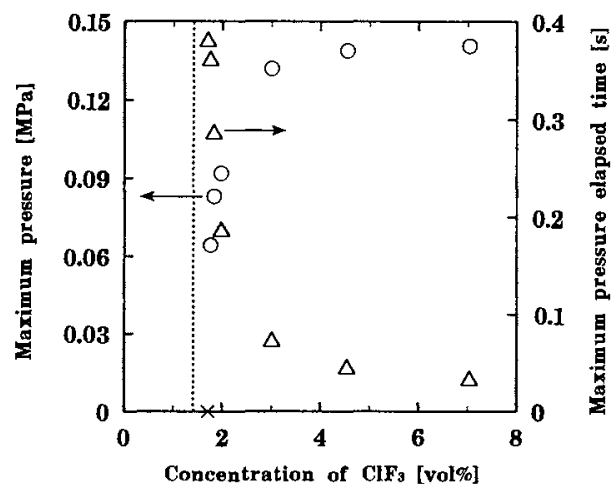

FIGURE 8. Variation of the pressure increment and the elapsed time to the maximum pressure increment with the $\mathrm{ClF}_{3}$ concentration for hydrogen. Concentration of hydrogen was 3.0 vol\%. 
reacts with $\mathrm{H}_{2}$ at the equivalent molar ratio. From this result, the reaction between them was expected as

$$
\mathrm{C} \ell F_{3}+H_{2} \rightarrow 2 H F+C \ell F . \quad \Delta \mathrm{H}=-433.8 \mathrm{~kJ} / \mathrm{mol}
$$

This is not the so-called complete combustion reaction. This reaction also includes the decomposition reaction of $\mathrm{ClF}_{3}$ implicitly, and relatively stable $\mathrm{ClF}$ still remains after the combustion reaction.

Figure 9 shows the flammability diagram of the $\mathrm{H}_{2} / \mathrm{ClF}_{3} / \mathrm{N}_{2}$ mixture. Solid circles means explosions occurred at an initial pressure $0.05 \mathrm{MPa}$, and open circles means explosions occurred at an initial pressure $0.1 \mathrm{MPa}$. The lower limiting concentrations for $\mathrm{ClF}_{3}$ and $\mathrm{H}_{2}$ are 1.7 vol $\%$ and $0.9 \mathrm{vol} \%$ at $0.05 \mathrm{MPa}$, and $1.2 \mathrm{vol} \%$ and $0.5 \mathrm{vol} \%$ at $0.1 \mathrm{MPa}$, respectively.

\section{CONCLUSION}

The combustion reactions of TEOS, ammonia, and hydrogen in chlorine trifluoride were investigated experimentally. TEOS was found to ignite spontaneously after mixing well with $\mathrm{ClF}_{3}$. Ammonia ignited spontaneously at contacted with $\mathrm{ClF}_{3}$. Hydrogen did not ignite spontaneously, but explosions occurred in a wide concentration range by application of an electric spark to a mixture with $\mathrm{ClF}_{3}$. From discussion on the limiting flammable concentrations, $\mathrm{ClF}_{3}$ was considered to decompose before reacting with the flammable gas, and the active $\mathrm{F}_{2}$ reacts alone with the fuel.

\section{ACKNOWLEDGMENT}

The authors wish to thank Messrs. M. Aramaki and T. Enomoto of the Central Glass Corporation for their technical and financial support.

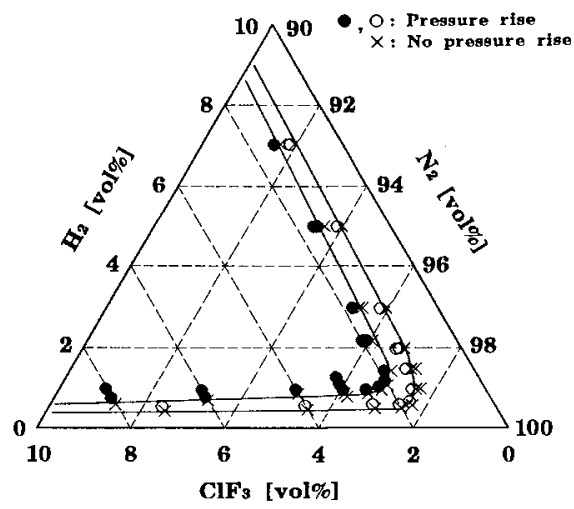

FIGURE 9. Flammability diagram of the $\mathrm{H}_{2} / \mathrm{ClF}_{3} / \mathrm{N}_{2}$ mixture. 


\section{REFERENCES}

1. Ohtani, H., Horiguchi, S., Urano, Y., Tokuhashi, K., Iwasaka, M. and Kondo, S. "Flammability Limits of Arsine and Phosphine", Combustion and Flame, 76, 307-310, 1989.

2. Tokuhashi, K., Horiguchi, S., Urano, Y., Iwasaka, M., Ohtani, H. and Kondo, S., "Premixed Silane-Oxygen-Nitrogen Flames", Combustion and Flame, 82, 40-50, 1990.

3. Lee, S.G., Ohtani, H., Uehara, Y., and Aramaki, M., "Experimental Study on Flammability Limit of Chlorine Trifluoride/Dichlorosilane/Nitrogen Mixture", J. Loss Prevention, 5, 192-195, 1992.

4. Lee, S.G., Ohtani, H., Uehara, Y., and Enomoto, T., "Spontaneous Ignition of $\mathrm{SiH}_{4}$ in $\mathrm{ClF}_{3}$ ", Combustion Science and Technology, Japanese Ed., 1, 129-134, 1993.(in Japanese) 5. Stein, L., Halogen Chemistry, p. 133, Academic Press, London and New York, 1967. 